\title{
A review of knowledge transfer tools in knowledge-intensive organisations
}

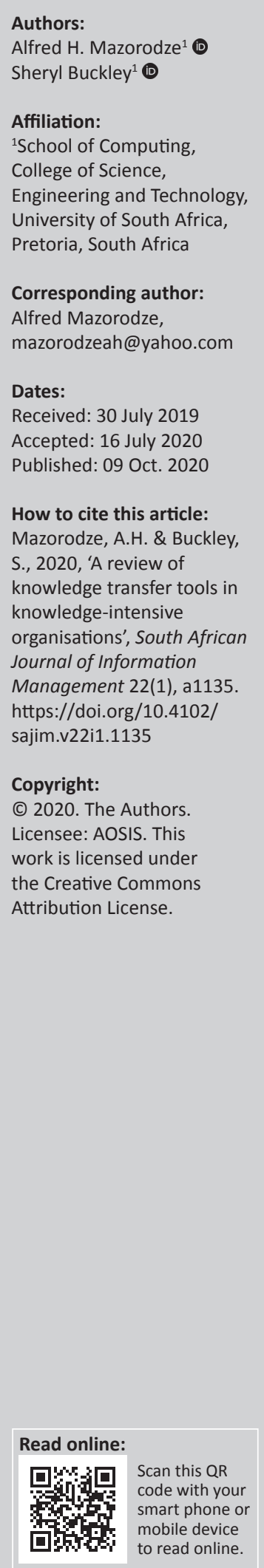

Background: Knowledge transfer is very important in knowledge-intensive organisations in both developed and developing countries. A knowledge-intensive organisation is an organisation whose operations depend on specialised knowledge. Knowledge-intensive organisations lose intellectual property when experienced employees retire from their jobs. To avoid knowledge loss, skills and expertise should be transferred from experts to non-experts on time. Knowledge transfer tools allow sharing of tacit knowledge between and amongst staff members. The study provides an analysis and review of the most effective knowledge transfer tools in knowledge-intensive organisations because an organisation's success is based on its ability to transfer knowledge.

Objectives: The study had two main objectives: to identify and review knowledge transfer tools used in knowledge-intensive organisations and to recommend the best knowledge transfer tool that can be used in organisations for the purpose of enhanced competitive advantage.

Method: A well-structured questionnaire was used to collect quantitative data from the research participants in knowledge-intensive organisations in Namibia.

Results: The results indicate that the most effective knowledge transfer tool in knowledgeintensive organisations is a community of practice; $40 \%$ of the participants considered the tool effective, and $27 \%$ considered it to be very effective. This was followed by the mentoring tool, which was ranked $54 \%$ effective and $11 \%$ very effective by the participants because it exposes mentees to new ideas and new ways of thinking. Storytelling was ranked $28 \%$ effective and $17 \%$ very effective because it is a natural learning process. Succession plans were ranked $21 \%$ effective and $12 \%$ very effective because having succession plans in place on time is essential for organisational success. Coaching and knowledge repositories were ranked below $20 \%$ on knowledge transfer effectiveness. From the findings, we conclude that the most effective tool for knowledge transfer in knowledge-intensive organisations is communities of practice (CoP) followed by mentoring, storytelling, succession plans, coaching and finally knowledge repositories.

Conclusion: The most effective knowledge transfer tool in knowledge-intensive organisations is Communities of Practice, followed by mentoring, storytelling, succession plans and lastly coaching. Communities of Practice are important for knowledge transfer in that they encourage and promote teamwork through discussions and knowledge sharing amongst employees. The study therefore recommends the creation of such Communities of Practice in knowledge-intensive organisations for effective knowledge transfer and sharing.

Keywords: communities of practice; coaching; knowledge repositories; knowledge transfer; mentoring; storytelling; succession planning.

\section{Introduction}

Knowledge is an organisation's largest asset, and it must be managed effectively. Knowledge can be obtained either by transmission from the person who has it, by instruction or by extracting it from experience (Kim, Byung \& Lee 2012). The European Framework for Knowledge Management (2015) define knowledge as an amalgamation of data and information, where expert opinion and experience are added to result in a valued asset that could be used to improve an organisation's decision-making capabilities. Data is described by Pearlson and Saunders (2004) as discrete and objective facts that are not organised and processed and do not have any specific meaning. Information is data that have been shaped into a form that is meaningful and useful to humans. Turban, Rainer and Potter (2005) stress that knowledge is data and/or information that has been 
processed and organised to convey understanding, experience and expertise as they apply to a current problem. Thus, knowledge consists of a mixture of information, values, rules and experiences from different sources. The muchneeded knowledge resides in the heads of people, and it greatly influences organisational success.

According to Lievre and Tang (2015), knowledge transfer activities help employees to transfer expertise to others on time. During knowledge transfer, people collaborate and exchange important ideas. Some of the knowledge transfer tools or activities commonly used in knowledge-intensive organisations include communities of practice $(\mathrm{CoP})$, succession plans, coaching, storytelling, knowledge repositories, mentoring and job rotation, amongst others (Wenger 2014; Whyte \& Classen 2012). Knowledge transfer activities are necessary and can be fixed into the organisational structures and processes. We can therefore infer that knowledge transfer activities allow sharing of important knowledge in organisations, a point that Reiche (2011) also emphasises.

This review only looks at the knowledge transfer tools or activities that might accelerate innovation and boost productivity in knowledge-intensive organisations. It is important to highlight here that the knowledge transfer tools analysed and discussed here are not the end-all. The research was conducted with the following aims and objectives:

- to identify and review the knowledge transfer tools used in knowledge-intensive organisations

- to analyse and recommend the best knowledge transfer tool that can be used in knowledge-intensive organisations for the purpose of enhanced competitive advantage.

\section{Theoretical framework and literature review}

Nonaka and Takeuchi (1995) classify knowledge into two specific categories: 'tacit' and 'explicit'. Tacit knowledge is resident in an individual's mind. Tacit knowledge is deeply rooted in an individual's experiences, ideals, values and emotions (Nonaka \& Takeuchi 1995:8). Explicit knowledge refers to knowledge that can be expressed and explained meaningfully in words and numbers (Davenport \& Prusak 2000). Explicit knowledge can be communicated to other parties, and it can be processed by humans or machines programmed to perform the tasks. It is vital to understand these two types of knowledge and the mechanisms organisations engage to manage them. Becerra-Fernandez and Sabherwal (2010) made the useful observation that it was difficult to explicate tacit knowledge and then make it accessible for use by others.

Tacit knowledge can be transferred through mentorship and coaching (Davenport \& Prusak 2000). With explicit knowledge, knowledge transfer is performed via services and documented processes, through which one appropriates the protocols and eventually takes ownership of this explicit knowledge. Knowledge transfer involves the focussed and purposeful communication of knowledge from the sender to a known receiver (King 2006). Knowledge transfer is considered by Knowledge Management (KM) practitioners as an integral part of every organisation. Knowledge Management practitioners (Grant 1996; Jang \& Ko 2014; Leibowitz 2012; Liu 2016; Nonaka \& Takeuchi 1994) concur that for knowledge to have an organisational impact, it must be transferred or shared. Kalling (2003) maintains that the organisation's success can be based on its ability to transfer knowledge. In line with this view, Hendriks (2009) contends that knowledge transfer provides opportunities to enhance the organisation's competitive advantage.

\section{Literature review}

McDonald and Cater-Steel (2016) describe CoP as an integrated approach for transferring knowledge through formal and/or informal groups. Schiavone (2013) adds that CoP can be formally established or can evolve spontaneously. Wenger (2014) adds that CoP are powerful manifestations of informal learning. Communities of practice are therefore effective knowledge transfer tools, as they permit employees to manage change by clarifying their roles in those organisations. These CoP have the ability to link professionals for knowledgesharing purposes in knowledge-intensive organisations. A CoP can be Information Technology (IT)-based or non-IT, depending on the characteristic considerations of the community members (Heeyoung \& Ilsang 2014). According to Durst and Wilhelm (2012), succession plans identify and develop employees to fill in positions in organisations at the right time. Knowledgeintensive organisations lose the knowledge and skills of experts when they retire from their jobs. Rothwell (2010) argues that the heart of succession plans is the epicentre of KM. Succession plans are an ongoing process that focusses on the knowledge transfer necessitated by an ageing workforce. Knowledge transfer through succession plans represents a proactive step towards employee empowerment, which leads to increased organisational responsiveness.

Coaching is a knowledge transfer tool that focusses on immediate problems and opportunities. Abbott (2014) argues that coaching entails guiding the trainee so as to fuse the operational knowledge that increases organisational performance. Management Mentors (2019) underscore the significance of coaching to perfect employee skills in an organisation. Stuhlmann (2012) defines storytelling as narratives that constitute operational knowledge. Research by Whyte and Classen (2012) proves that storytelling is a vital tool for transferring tacit knowledge, allowing sharing of deeper knowledge, which may boost the organisation's knowledge. An organisation that shares knowledge amongst its staff will certainly benefit from the knowledge-sharing efforts. Leblanc and Hogg (2010) argue that storytelling as a knowledge transfer technique allows organisations to discover tacit knowledge, as it is a natural learning process. Moreover, storytelling can be used to share lessons learnt from projects with coworkers who did not participate in the activity. Thus, storytelling can be used to build a shared understanding amongst employees in an organisation. 
As defined by Leibowitz (2012), knowledge repositories are online storehouses of expertise and documentation about a particular domain. Knowledge repositories can be considered online self-help, as they make it easy to find relevant information and resources. Liu (2016) advises that organisations must develop means of documenting organisational knowledge. Relational databases are some of the technologies commonly used in building knowledge repositories for increased organisational efficiency. The American Productivity and Quality Center (APQC) (2010) adds that knowledge repositories support artificial intelligence technologies, including those used for electronic discussion groups, decision support systems, databases, expert systems and best practices. Mentoring is also considered a vital tool for knowledge transfer from experts to non-experts (Young 2013). The main aim of mentoring is to encourage that the individual reflect on the job as a whole (Rooney 2014). In most modern organisations, mentoring creates an organisational culture, which improves organisational performance. Knowledge transfer is highly likely to take place in a decentralised organisational structure, a point which is quite consistent in the literature (Liu 2016). Thus, mentoring provides specialised socialisation and personal support to facilitate knowledge transfer amongst employees.

The passion to share by and amongst the employees is very important for improving organisational performance (Wang \& Noe 2010). Knowledge sharing and transfer generates new ideas, increases operational efficiency and helps employees to stay motivated. These knowledge-transferring activities should be linked to a proper organisational strategy that is aligned with the organisational objectives. The strategy should be based on the best possible design for creating, maintaining, transferring and applying organisational knowledge to reach the defined goals as advised by Grant (1996). From the submissions by various authors above, it becomes very clear that knowledge transfer simulates growth and innovation in organisations. Liu (2016) is of the view that knowledge transfer reduces the loss of an organisation's know-how.

\section{Research design and methodology}

A survey strategy was used to collect data from purposefully selected research participants in Namibia, a developing country in southern Africa. The participants were drawn from selected public and private knowledge-intensive organisations in Namibia. Quantitative data were collected by using paper-based questionnaires and analysed by using the Microsoft Office Excel 2016 package. Tests for internal consistency were performed to increase the validity and reliability of the findings. The sample had 112 participants from the knowledge-intensive organisations identified, and interestingly, the response rate was $100 \%$.

\section{Results and discussion}

The participants responded to the questions asked as shown in Table 1. The question asked was 'How effective are the following activities for knowledge transfer in your organisation?' The question sought to measure the usefulness of the knowledge transfer tools in the selected public and private organisations.

According to the data shown in Table 1, the most effective knowledge transfer activity is a $\mathrm{CoP}$, which was classified as very effective $(27 \%)$ and effective $(40 \%)$ by the participants. This was followed by mentoring, which was ranked based on a percentage as very effective (11\%) and effective (54\%). Succession plans were ranked based on a percentage as very effective (12\%) and effective (21\%). Storytelling was also considered an effective knowledge transfer tool, with $17 \%$ of the participants considering the tool as effective and $28 \%$ as very effective. Coaching and knowledge repositories were not considered very useful tools for knowledge transfer, and both had less than $20 \%$ representation. The following sections present and analyse the information in Table 1 in the form of pie charts for each knowledge transfer tool or activity.

\section{Communities of practice}

According to the data gathered from the participants and presented in Figure 1, CoP were found to be effective in organisations by $40 \%$ of the participants. This was followed by $27 \%$ of the participants who considered CoP as very effective. It emerged that $24 \%$ of the participants had no opinion on the effectiveness of $\mathrm{CoP} ; 6 \%$ and $3 \%$ considered $\mathrm{CoP}$ as somewhat effective and not effective, respectively. Considering a CoP $40 \%$ effective as adjudged by the participants might mean that the participants to some extent share a common sense of purpose. According to Jang and Ko (2014), knowledge assessment determines the need for a CoP, with its three elements of the domain, the community and the practice. Community of practice objectives should be established and linked to the organisational objectives. Membership penetration and growth should be analysed in a CoP to see how the community has grown. A knowledge transfer activity does not assess whether learning occurs, perhaps that is why

TABLE 1: Effectiveness of knowledge transfer activities $(N=112)$.

\begin{tabular}{|c|c|c|c|c|c|c|c|c|c|c|}
\hline \multirow{2}{*}{$\begin{array}{l}\text { Knowledge transfer tool or } \\
\text { activity }\end{array}$} & \multicolumn{2}{|c|}{ Very effective } & \multicolumn{2}{|c|}{ Effective } & \multicolumn{2}{|c|}{ No opinion } & \multicolumn{2}{|c|}{ Somewhat effective } & \multicolumn{2}{|c|}{ Not effective } \\
\hline & $n$ & $\%$ & $n$ & $\%$ & $n$ & $\%$ & $n$ & $\%$ & $n$ & $\%$ \\
\hline Communities of practice & 30 & 27 & 45 & 40 & 27 & 24 & 7 & 6 & 3 & 3 \\
\hline Succession planning & 13 & 12 & 24 & 21 & 42 & 38 & 4 & 4 & 29 & 26 \\
\hline Coaching & 5 & 5 & 16 & 14 & 63 & 56 & 17 & 15 & 11 & 10 \\
\hline Storytelling & 19 & 17 & 31 & 28 & 21 & 19 & 34 & 30 & 7 & 6 \\
\hline Knowledge repositories & 8 & 7 & 6 & 5 & 82 & 73 & 16 & 4 & 0 & 0 \\
\hline Mentoring & 12 & 11 & 61 & 54 & 25 & 22 & 14 & 13 & 0 & 0 \\
\hline
\end{tabular}




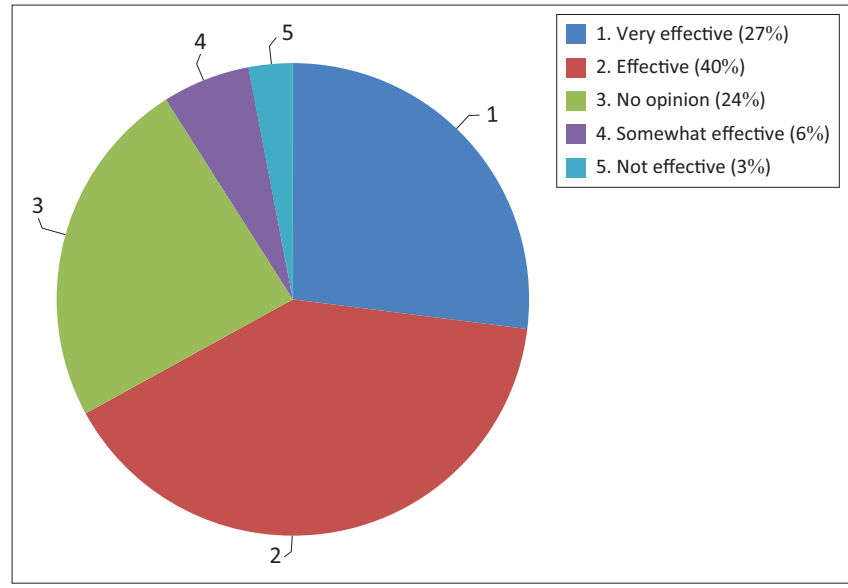

FIGURE 1: Participants' opinions of communities of practice as a knowledge transfer tool $(n=112)$

some $3 \%$ of the participants considered a CoP as not effective for transferring knowledge in an organisation.

\section{Succession planning}

Succession plans were considered $21 \%$ effective by the participants. Correspondingly, $12 \%$ of the participants reflected that succession plans were very effective, whilst the other $37 \%$ had no opinion on the effectiveness of succession plans. Moreover, $4 \%$ of the participants considered succession plans as somewhat effective, whilst the other $26 \%$ considered succession plans not effective at all. When employees retire, organisations face the loss of intellectual and institutional experience, memory and capital for problem-solving. One way of overcoming this challenge is to introduce succession plans to maintain organisational knowledge. Knowledge is the foundation of human capital, and the ability to attract and retain knowledge is an important component of innovation (Young 2013). Succession plans ensure an ongoing availability of talent. The responses from the participants are presented in Figure 2.

\section{Coaching}

Coaching refers to an interactive process through which managers aim to solve performance problems (Graduate Mentoring Guidebook 2015). From the empirical evidence gathered from the participants, it was found that coaching was very effective and effective by $14 \%$ and $5 \%$ of the respondents, respectively. The main goal of coaching is to correct inappropriate behaviour, improve performance and impart practical skills. A small percentage of $10 \%$ considered coaching as not effective, and 15\% considered coaching as somewhat effective. A median percentage $(56 \%)$ had no opinion on the effectiveness of coaching. According to the Management Mentors (2019), coaching is task oriented and is short term, which is performance driven. The focus of coaching is on immediate problems and opportunities; thus coaching increases productivity by fostering a positive work culture. At individual level, coaching results in the development of self-awareness

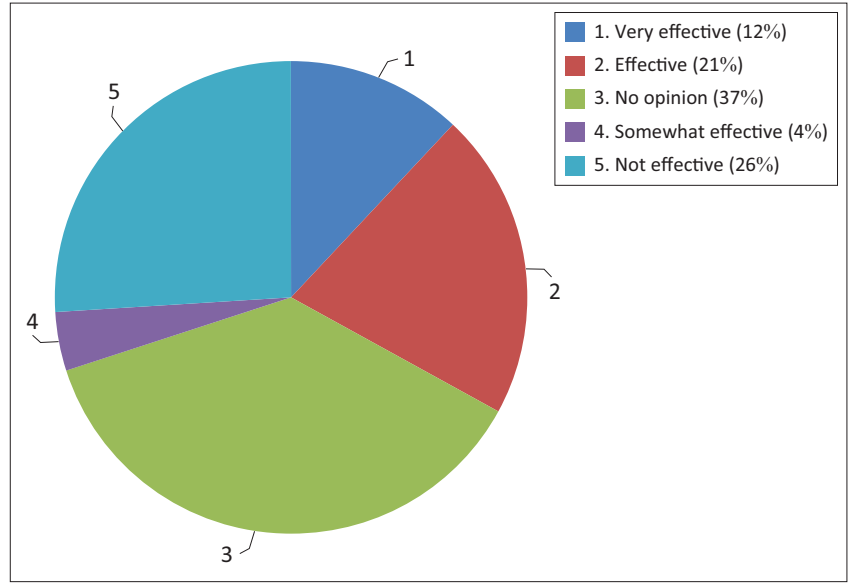

FIGURE 2: Participants' opinions of succession plans for knowledge transfer $(n=112)$.

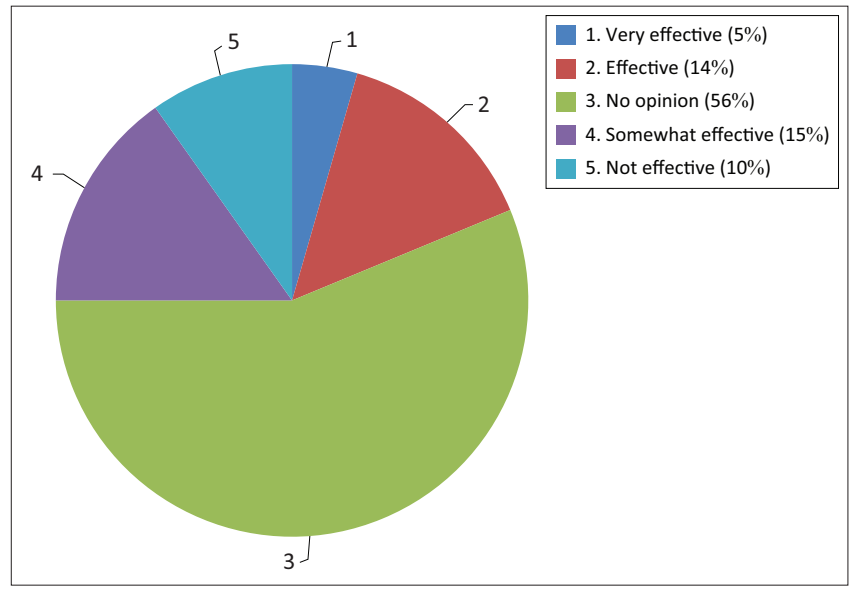

FIGURE 3: Participants' opinions on coaching for knowledge transfer in organisations $(n=112)$.

and greater responsibility. Most importantly, coaching motivates people and facilitates the adoption of a new organisational culture. The responses elicited from the participants are presented in Figure 3.

\section{Storytelling}

Storytelling is used to transfer experts' knowledge to the junior and younger generation of employees (Whyte \& Classen 2012). Moreover, storytelling is used to share lessons learnt from projects with coworkers and other peers. In this study, $17 \%$ and $28 \%$ of the participants considered storytelling as very effective and effective, respectively. It emerged that $30 \%$ of the participants considered storytelling as somewhat effective. On the other hand, $6 \%$ of the participants did not see storytelling as effective; thus they considered the tool not effective at all. The actual percentages of the responses from the participants are shown in Figure 4. According to Whyte and Classen (2012), storytelling is a vital tool for transferring tacit knowledge, and it has been found to allow for sharing of deeper information and knowledge. Arguably, storytelling is one of the best ways to transfer tacit knowledge, in the sense that the storyteller is able to transfer knowledge in a way that people understand easily. Most learning processes take place 


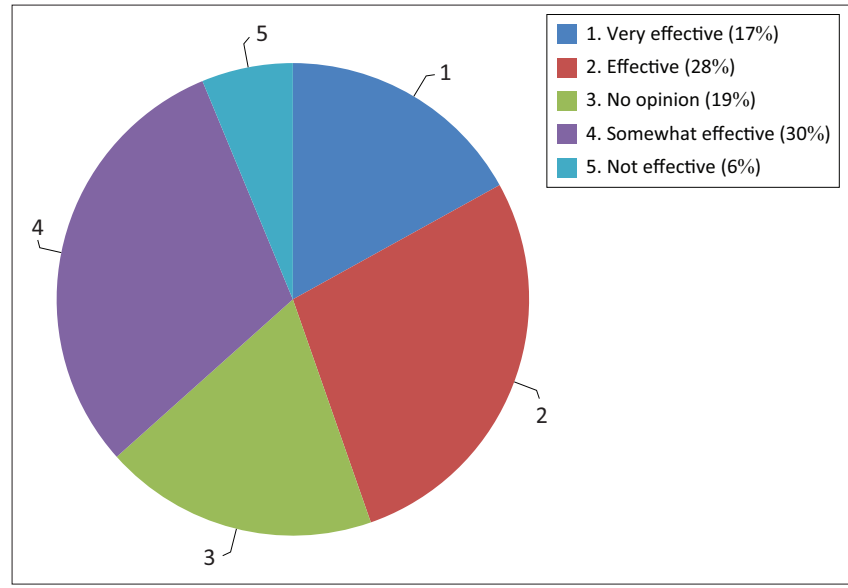

FIGURE 4: Participants' opinions of storytelling as a knowledge transfer tool $(n=112)$.

through storytelling; hence, the participants considered the tool so effective.

\section{Knowledge repositories}

Leibowitz (2012) defines knowledge repositories as online storehouses of expertise and documentation about a specific domain and discipline. Very few of the participants at the organisations studied had used knowledge repositories, and because of this, they had no opinion on the effectiveness of knowledge repositories (73\%). Out of the total participants, $14 \%$ considered knowledge repositories as somewhat effective. Only $6 \%$ considered knowledge repositories as effective. The individual responses about the effectiveness of knowledge repositories from the participants are shown in Figure 5. Concisely, knowledge repositories are private databases that manage enterprise information. Froman organisational perspective, knowledge repositories make it easy to find relevant information and knowledge. Knowledge repositories help organisations connect people with expertise via discussion forums and online searchable libraries. Some sources, like the Data Mining Techniques (Alton 2011), refer to knowledge repositories as data warehouses. Most importantly, knowledge repositories reduce training time for new staff, and they also help uncover automation opportunities via online self-help. Despite all the visible advantages of knowledge repositories, a great percentage of participants had no opinion on knowledge repositories.

\section{Mentoring}

Mentoring was found to be effective at the specific organisations studied. In this study, $54 \%$ of the participants considered mentoring as effective because skills have to be transferred from more experienced workers to less experienced workers though mentorship. None of the participants considered mentoring as ineffective. Twentytwo per cent had no opinion on the effectiveness of mentoring, and only $11 \%$ of the participants considered mentorship as very effective. The other $13 \%$ considered mentoring as somewhat effective. The actual responses from participants

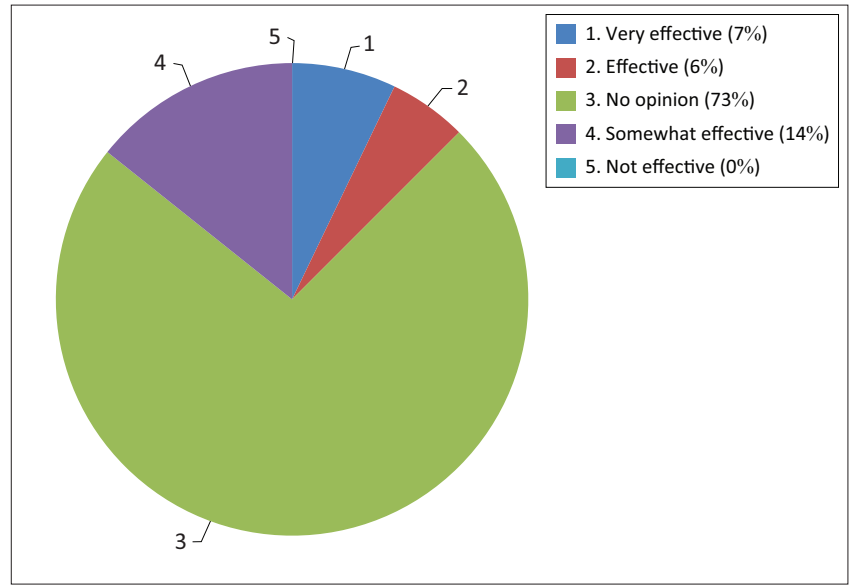

FIGURE 5: Participants' opinions of knowledge repositories as knowledge transfer tools $(n=112)$.

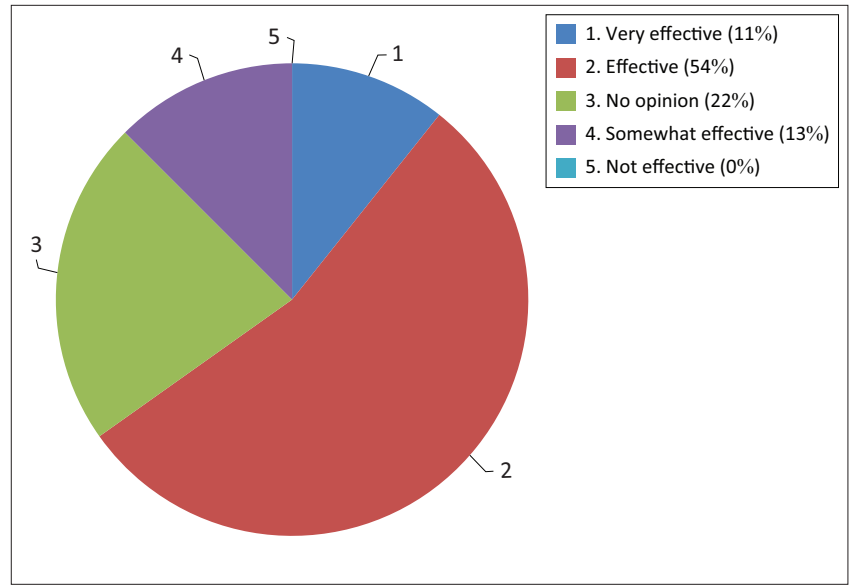

FIGURE 6: Participants' opinions of mentoring as a knowledge transfer tool $(n=112)$.

are shown in Figure 6. Mentoring provides professional socialisation to facilitate knowledge transfer in knowledgeintensive organisations. Mentoring in organisations is needed to increase skill levels; hence $54 \%$ of the participants identified the tool as effective in knowledge transfer. To the mentees, mentoring improves self-confidence and encourages reflection on their practice (Management Mentors 2019). To the mentors, mentoring provides opportunities for reflecting on their own practice and enhancing peer recognition.

\section{Conclusion}

In knowledge-intensive organisations, it has been found that the most effective knowledge transfer tool is CoP; $40 \%$ of the participants considered this tool to be effective, and $27 \%$ considered it very effective. Communities of practice are important for knowledge transfer in that they encourage and promote teamwork through discussions and knowledge sharing amongst employees (Wenger 2014). This was followed by the mentoring tool, which was ranked $54 \%$ effective and $11 \%$ very effective by the participants. Mentoring exposes mentees to new ideas and new ways of thinking, which may accelerate and boost organisational effectiveness. Storytelling was ranked $28 \%$ effective and $17 \%$ very effective because it is a natural teaching and learning tool in organisations, which 
improves communication. Succession plans were ranked 21\% effective and $12 \%$ very effective because the loss of organisational memory should not be underestimated. Having succession plans in place on time is essential for organisational success. Coaching and knowledge repositories were ranked below 20\% effective. We can therefore conclude that the most effective tool for knowledge transfer in knowledge-intensive organisations is $\mathrm{CoP}$ followed by mentoring, storytelling, succession plans, coaching and finally knowledge repositories. The study therefore recommends the creation of CoP in knowledge-intensive organisations for effective knowledge transfer and knowledge sharing. In a CoP, people collaborate regularly to share information, improve their skills and actively work on advancing the general knowledge of the domain.

\section{Acknowledgements}

The authors thank all the participants who participated in this study and the language editor who edited this piece of work.

\section{Competing interests}

The authors declare that no competing interests exist.

\section{Authors' contributions}

A.H.M. collected the data from the knowledge-intensive organisations in Namibia and wrote the article. S.B. assisted by giving direction and the necessary support in writing the research article. Both authors approved the final version of the manuscript.

\section{Ethical consideration}

The study received ethical clearance from the university of South Africa's College of Science, Engineering and Technology's Research and Ethics Committee, with reference number: 009/AHM/2017/CSET_SOC.

\section{Funding information}

This research received no specific grant from any funding agency in the public, commercial or not-for-profit sectors.

\section{Data availability statement}

Data sharing is not applicable to this article as no new data were created or analysed in this study.

\section{Disclaimer}

The views and opinions expressed in this article are those of the authors and do not necessarily reflect the official policy or position of any affiliated agency of the authors.

\section{References}

Abbott, G.N., 2014, 'Cross-cultural coaching: A paradoxical perspective', in E. Cox T. Bachkirova \& D. Clutterbuck (eds.), The complete handbook of coaching, 2nd edn., pp. 295-317, Sage, London.

Alton, L., 2011, The 7 Most Important Data Mining Techniques, viewed 20 August 2020 from https://www.datasciencecentral.com/profiles/blogs/the-7-most-importantdata-mining-techniques
American Productivity \& Quality Center (APQC), 2010, Best practice report, Measuring the Impact of Knowledge Management, Arlington, TX

Becerra-Fernandez, I. \& Sabherwal, R., 2010, Knowledge Management systems and processes, Armonk, New York, NY.

Davenport, T.H. \& Prusak, L., 2000, Working knowledge: How organizations manage what they know, Harvard Business School Press, Boston, MA

Durst, S. \& Wilhelm, S., 2012, 'Knowledge management and succession planning in SMEs', Journal of Knowledge Management 16(4), 637-649. https://doi. org/10.1108/13673271211246194

European Framework for Knowledge Management, 2015, Business Knowledge Management: A study on market prospects, business needs and technological trends: Final report, viewed 15 August 2018, from https://ec.europa.eu/ information_society/doc/library/business_knowledge_management.pdf

Graduate Mentoring Guidebook, 2015, viewed 10 May 2015, from http://www.unl. edu/mentoring/introduction

Grant, R.M., 1996, 'Towards a knowledge-based theory of the firm', Strategic Management Journal 17(2), 109-122. https://doi.org/10.1002/smj.4250171110

Heeyoung, J. \& Ilsang, K., 2014, 'The factors influencing communities of practice activities and their impact on relationship commitment and individual performance', Journal of Knowledge Management 18(1), 75-91. https://doi. org/10.1108/JKM-06-2013-0233

Hendriks, P., 2009, 'Why share knowledge? The influence of ICT on the motivation for knowledge sharing', Knowledge and Process Management 6(2), 91-100.

Jang, O. \& Ko, K., 2014, 'Factors influencing CoP and their impact on relationship commitment and individual performance', Journal of Knowledge Management 18(1), 75-91. https://doi.org/10.1108/JKM-06-2013-0233

Kalling, T., 2003, 'Organization-internal transfer of knowledge and the role of motivation: A qualitative case study', Knowledge and Process Management 10(2), $115-126$.

Kim, H., Byung, G.K. \& Lee, S., 2012, 'An integrated view of knowledge management for performance', Journal of Knowledge Management 16(2), 183-203. https://doi. org/10.1108/13673271211218807

King, W.R., 2006, 'Knowledge Management and Organizational Learning', Annals of Information Systems 4, 3-13. https://doi.org/10.1007/978-1-4419-0011-1_1

Leblanc, S.M. \& Hogg, J., 2010, Storytelling in knowledge management: An effective tool for uncovering tacit knowledge, viewed 20 May 2017, from http://www. tlainc.com/articl222.htm

Leibowitz, J., 2012, Knowledge management handbook: Collaboration and socia networking, 2nd edn., CRC Press, Taylor and Francis Group, Boca Raton, FL.

Lievre, P. \& Tang, J., 2015, 'SECl and inter-organizational and intercultural knowledge transfer: A case-study of controversies around a project of co-operation between France and China in the health sector', Journal of Knowledge Management 19(5), 1069-1086

Liu, S., 2016, Introduction to knowledge management, viewed 21 May 2017, from http://web.archive.org/web/20160319233812/Introduction_to_Knowledge Management.htm

Management Mentors, 2019, Building strong workforce with mentoring, viewed 22 September 2020, from https://www.mentoringcomplete.com/

McDonald, J. \& Cater-Steel, A. (eds.), 2016, Communities of practice: Facilitating social learning in higher education, Springer, Singapore.

Nonaka, I. \& Takeuchi, H., 1994, 'A dynamic theory of organizational knowledge creation', Organization Science 5(1), 14-37.

Nonaka, I. \& Takeuchi, H., 1995, The Knowledge-creating company: How Japanese companies create dynamics of innovation, Oxford University Press, New York, NY.

Pearlson, K.E. \& Saunders, C.S., 2004, Managing and Using Information Systems: A Strategic Approach, Wiley, New York, NY.

Reiche, B.S., 2011, 'Knowledge transfer in multinationals: The role of in patriates' boundary spanning', Human Resource Management 50(3), 365-389. https://doi. org/10.1002/hrm.20423

Rooney, J., 2014, 'Knowledge management and organisational learning', Proceedings of the 11th International Conference on Intellectual Capital, University of Sydney, Sydney.

Rothwell, W.J., 2010, Effective succession planning: Ensuring leadership continuity and building talent from within, 4th edn., Amacom, New York, NY.

Schiavone, F., 2013, Communities of Practice and Vintage Innovation. A Strategic Reaction to Technological Change, Springer, New York, NY. https://doi. org/10.1007/978-3-319-01902-4

Stuhlmann, D.D., 2012, Knowledge management terms, viewed 15 May 2017, from http://home.earthlink.net/ ddstuhlman/defin1.htm.

Turban, E., Rainer, R.K. \& Potter, R.E., 2005, Introduction to information technology, Wiley, New York, NY.

Wang, S. \& Noe, R.A., 2010, 'Knowledge sharing: A review and directions for future research', Human Resource Management Review 20(2), 115-131. https://doi. org/10.1016/j.hrmr.2009.10.001

Wenger, E., 2014, Learning in landscapes of practice: Boundaries, identity, and knowledgeability in practice-based learning, Routledge, Abingdon.

Whyte, G. \& Classen, S., 2012, 'Using storytelling to elicit tact knowledge from SMEs', Journal of Knowledge Management 16(6), 950-962. https://doi.org/10.1108/ 13673271211276218

Young, R., 2013, Knowledge management for the public sector, Asian Productivity Organization, Tokyo. 